\title{
Dynamic compressive strength and crushing properties of expanded polystyrene foam for different strain rates and different temperatures
}

Anastasiia Krundaeva, ${ }^{a, b}$, Guido De Bruyne ${ }^{c, d}$, Francesco Gagliardi ${ }^{a}$, Wim Van Paepegem ${ }^{a}$

aDepartment of Materials Science and Engineering, Faculty of Engineering and Architecture, Ghent University, Technologiepark 903, B-9052 Zwijnaarde, Gent, Belgium;

Email: akrundaeva@gmail.com, Web Page: http://www.composites.ugent.be;

bSIM M3 program, Technologiepark 935, B-9052 Zwijnaarde, Gent, Belgium;

'Lazer Sport, Lamorinierestraat 37, 2018 Antwerpen, Belgium;

Email: Guido@lazersport.com, Web Page: http://www.lazersport.com;

dProduct Development, Faculty of Design Sciences, University of Antwerp, Ambtmanstraat 1, 2000 Antwerp, Belgium.

\section{Abstract}

In this study, static and dynamic compression and crushing tests were conducted on expanded polystyrene (EPS) foam for material characterisation at high strain rates. This was done to obtain the stress-strain curve for different temperatures and densities. An influence of the strain rate on the experimental data was shown. The resulting curves for modelling were extracted from the experimental data, which were obtained from high speed drop tower tests. The methodology for the processing of the experimental data for use in the finite element (FE) modelling was presented. The foam material model of LS-Dyna was used to simulate the dynamic compression process. This model is dedicated to modelling crushable foam with optional damping, tension cut-off, and strain rate effects. The adjustment of the material parameters for successful modelling has been reported. This FE model of EPS foam was validated with experimental data using impact on a "kerbstone" support. This model can be applied for simulation of dynamic loads on a bicycle helmet. It is useful for designing a reliable bicycle helmet geometry for different types of accidents.

Key words: foam; compressive deformation; strain rate; temperature effect; commercial software LS-DYNA. 


\section{Introduction}

Foam is used for energy management in a helmet. There are many types, but EPS foam is the choice for most bike helmets, because it has a high energy absorbing efficiency $[1,2]$. Several remarkable properties have been noted for EPS foam such as: light weight, good thermal insulation, moisture resistance, durability, acoustic absorption and low thermal conductivity, reduction on material costs, excellent energy dissipation properties [3].

The foam in a helmet fulfils two impact-mitigating functions. First, it redistributes a localised external force over a larger area, reducing the local stress on the skull. Second, it sets an upper limit to the magnitude of this distributed force, as determined by the plateau-stress of the foam. The key step in selecting a suitable helmet liner material is to define the acceptable maximum value for this distributed force. Dynamic processes in this type of materials show interesting physical phenomena. An optimal energy-absorbing material needs to dissipate the kinetic energy of the impact while keeping the force on it below a certain limit, thus resulting in a non-dangerous deceleration on the occupants [1]. Of course, also the geometry of the protective structure will affect the load distribution during impact and the capacity to absorb elastic energy, which controls rebound.

EPS foams are well suited for the above mentioned application. They can undergo large compressive deformation and absorb energy. Energy is dissipated through cell bending, buckling or fracture, but the stress is generally limited by the long and flat plateau of the stress-strain curve [4]. This behaviour explains the high energy efficiency that can be obtained with foamed materials. Moreover, for the same amount of dissipated energy, a foam specimen always gives a maximum force lower than a corresponding solid specimen of equal volume made of the same material. EPS foam is also relatively insensitive to temperature changes as compared to most other closed cell foams. It keeps its energy absorbing capacities in both cold $\left(-20^{\circ} \mathrm{C}\right)$ and hot conditions $\left(+50^{\circ} \mathrm{C}\right)$, as defined by the European bicycle helmet standard EN1078 [5]. Insight into the dynamic behaviour of the EPS will help creating a FE model of this material, while it may also aid to seek for alternatives.

The foam density has an influence on the foam microstructure and accordingly on the properties of the foam $[6,7]$. The performance of foams has thus to be studied as a function of several parameters such as density, microstructure and also the strain rate imposed during dynamic loading. These studies have been summarised in several publications $[4,8,9]$. The compressive stress-strain behaviour of these foams has been investigated over a wide range 
of engineering strain rates from 0.01 to $1500 \mathrm{~s}^{-1}$ in order to demonstrate the effects of foam density and strain rate on the initial collapse stress and the hardening modulus in the postyield plateau region. Unfortunately, none of these studies were done on EPS foam. The data in these papers can help to construct and validate predictive models, however, because this material is multi-scale (constitutive beads at the mesoscopic scale, that are made of microscopic closed cells) $[10,11,12]$.

The results of an extensive experimental investigation into the static and dynamic mechanical properties of EPS foam were presented in a paper by Wensu Chen et al. [13]. This paper presents static and dynamic compressive and tensile test data of EPS with densities of $13.5 \mathrm{~kg} / \mathrm{m}^{3}$ and $28 \mathrm{~kg} / \mathrm{m}^{3}$ at different strain rates. The dynamic strength, Young's modulus and energy absorption capacities of the two EPS foams at different strain rates were obtained and presented in the paper. Based on the testing data, some empirical relations were derived. However, they did not explain how to apply the data from the experimental results. It is very important, because the strain rate in the test is not a constant. The observed maximum compressive strain rate in their experiment was approximately $2801 / \mathrm{s}$, not $5331 / \mathrm{s}$ as expected. Some testing results of the EPS foam under dynamic and static compressive loading have also been reported in the literature $[14,15]$. This data has been used to investigate a common foam constitutive model, and shows that strain rate effects become more pronounced at rates above approximately 1000/s. This work did not present a numerical model which can be used to predict EPS properties in simulations of dynamic responses to impact loads.

There are only a few articles about modelling EPS foam, especially with high dynamic strain rate. Quasistatic compression tests were conducted on the EPS crushable foam for material characterisation at low strain rates $(8.3 \times 10-3 \sim 8.3 \times 10-2 \mathrm{~s}-1)$ to obtain the stress strain curves [16]. In this work numerical analysis of compression tests was carried out to validate it against experimental results. Additionally, gravity-driven drop tests were carried out using a long rod projectile with hemispherical end that penetrated into the EPS foam block. The long rod projectile drop tests were simulated in LS-DYNA by using suggested parameter enhancements that allowed for the material damage and failure response to be computed precisely.

Another interesting article about finite element analysis (FEA) of EPS foam presents a multiple compressive loading and unloading of EPS foam [17]. Results of FEA packages 
ABAQUS and LS-DYNA were compared to compression test results and crushing diagrams for multiple loadings. For this simulation a material model was used, which did not include the influence of the foam strain rate. Masso-Moreu and Mills [18] presented work about dynamic compression of polystyrene foam pyramids. Finite element analysis in Abaqus was used in the numerical assessment of the compressive impact response of a range of two- and threedimensional truncated pyramidal polystyrene foam shapes, of the type used in protective packaging. Gerhard Slik et al. [19] did experimental and finite element analysis for material model validation of a high efficient energy absorbing foam. However, the material models of the foam were strain-rate independent in both works.

This article presents a detailed comparison of experimental data and numerical models for the dynamic compressive strength and crushing properties of expanded polystyrene foam with different strain rate and different temperature. The modeling was done in LS-DYNA. Validation of the EPS foam numerical model was done with tests using the "kerbstone" support.

\section{Experimental work}

\section{Dynamic compression test}

EPS foams can be used to absorb energy. The performance of these foams has to be studied as a function of several parameters such as density, microstructure and also the strain rate imposed during dynamic loading. Dynamic compression tests were conducted on cubic specimens of EPS foam with side length of $25 \mathrm{~mm}$ (Figure 1). They were cut from a foam plate. The size of the specimens was chosen to obtain a reasonable compromise between the maximum amount of relative compression of the entire group of specimens. During the experimental work four types of the EPS foam were used. Specimens were accurately measured and weighed before testing, and the average apparent density was calculated for each type of foam cube. The EPS foam have properties that depend on both topology and material [20]. EPS foam is actually a closed-cell extruded polystyrene foam. EPS foam is the correct term for any form of expanded polystyrene. The density of polystyrene is $1.0 \cdot 10^{-6} \mathrm{~kg} / \mathrm{mm}^{3}$. During the static tests, the Young's modulus and Poisson's ratio were extracted. The density, relative density, volume, mass, Young's modulus and Poisson's ratio of the foam material are listed in Table 1. 
Table 1: Average foam parameters, obtained from ten specimens.

\begin{tabular}{|c|c|c|c|c|}
\hline $\begin{array}{l}\text { Nominal density from } \\
\text { manufacturing, } \mathrm{g} / \mathrm{L}\end{array}$ & 60 & 80 & 100 & 120 \\
\hline mass, $\mathrm{g}$ & 1.15 & 1.43 & 1.94 & 2.12 \\
\hline Volume $\cdot 10^{3}, \mathrm{~mm}^{3}$ & 16.13 & 16.25 & 16.90 & 16.25 \\
\hline Density $\cdot 10^{-8}, \mathrm{~kg} / \mathrm{mm}^{3}$ & 7.16 & 8.82 & 11.50 & 13.10 \\
\hline Relative density $\cdot 10^{-2}, \mathrm{~kg} / \mathrm{mm}^{3}$ & 7.16 & 8.82 & 11.50 & 13.10 \\
\hline Young's modulus, MPa & 50.50 & 60.37 & 70.83 & 80.12 \\
\hline Poisson's ratio & 0.225 & 0.210 & 0.200 & 0.175 \\
\hline
\end{tabular}

With the aim to characterize the foam material, impact experiments were carried out by means of a Drop Tower Test Machine with flat impactor. Several drop heights and temperatures were tested to obtain different combinations of stress, strain and strain rate. The obtained data were properly organized for reaching material formulations, which could be generally used for a wide range of compression-dominated analyses. Displacement, velocity and acceleration were measured during the experiment with an Oscilloscope (Gen5i) and a 2D line grating method [21]. A flat anvil was used for the dynamic compression properties of the EPS foam. Each configuration was repeated 3 times. In general, 72 experiments were done. Throughout this experimental work three temperatures were used: room temperature $18^{\circ} \mathrm{C}$, low temperature $-20^{\circ} \mathrm{C}$ and high temperature $+50^{\circ} \mathrm{C}$. During one day, a group of the specimens were kept in a freezer with temperature $-20^{\circ} \mathrm{C}$ and another group of the specimens was kept in a heating chamber with temperature $50^{\circ} \mathrm{C}$. After one day the specimens were used in the experiments with Drop Tower Test Machine.

Upon examining the specimens after the compression test, no lateral expansion was observed as seen in Figure 1. The Drop Tower energy was $38.37 \mathrm{~J}$ when the temperature reached $50^{\circ} \mathrm{C}$. This proves that the EPS foam's Poisson's ratio was close to zero. The volume of the material is not conserved during compression. Instead, the density increases while the material is compressed. The Poisson's ratio plays an important role in the stress-strain diagrams. The initial and final cross section areas of the EPS crushable foams in compression remain constant. 


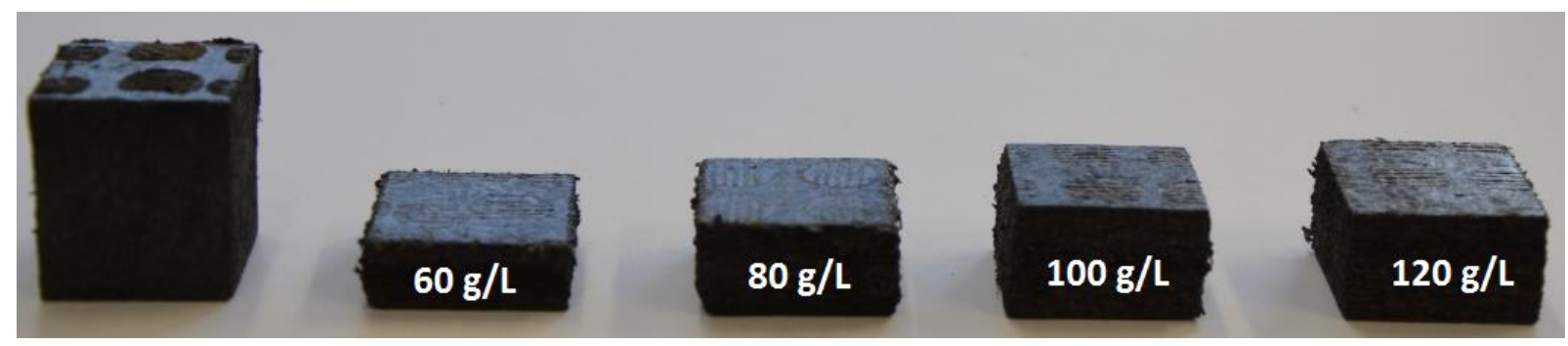

Figure 1. Results of dynamic compression test of EPS foam at high temperature $\approx 50^{\circ} \mathrm{C}$.

Consequently, it should be highlighted that a typical stress-strain curve obtained by foam compression can be divided in three different parts: 1) initial region, in which the material shows some stiffness due to the strength of the cell walls, 2) plateau region, where the cell walls gradually collapsed and 3) densification region, which begins when the cells have totally ruptured or collapsed and, therefore, the curve suddenly rises up. A large amount of energy was dissipated through the plateau region and the densification region $[22,23]$. However, the transition point between the stress plateau and the densification region was not clear. This is believed to be due to the different size of the foam cells and the permanent damage. The cell edges collapse by elastic or plastic buckling, while the faces of these closed cells bend and the bead walls mainly collapse by buckling. During dynamic compression tests, the degree of strength enhancement depends on the strain rate [24] but also on the complex microstructure of the foam and the entrapped gas in the closed cells $[25,26]$. The results of the dynamic compression test, when the drop tower energy was $38.37 \mathrm{~J}$ at room temperature $\approx 18^{\circ} \mathrm{C}$, are plotted in Figure 2 and 3.

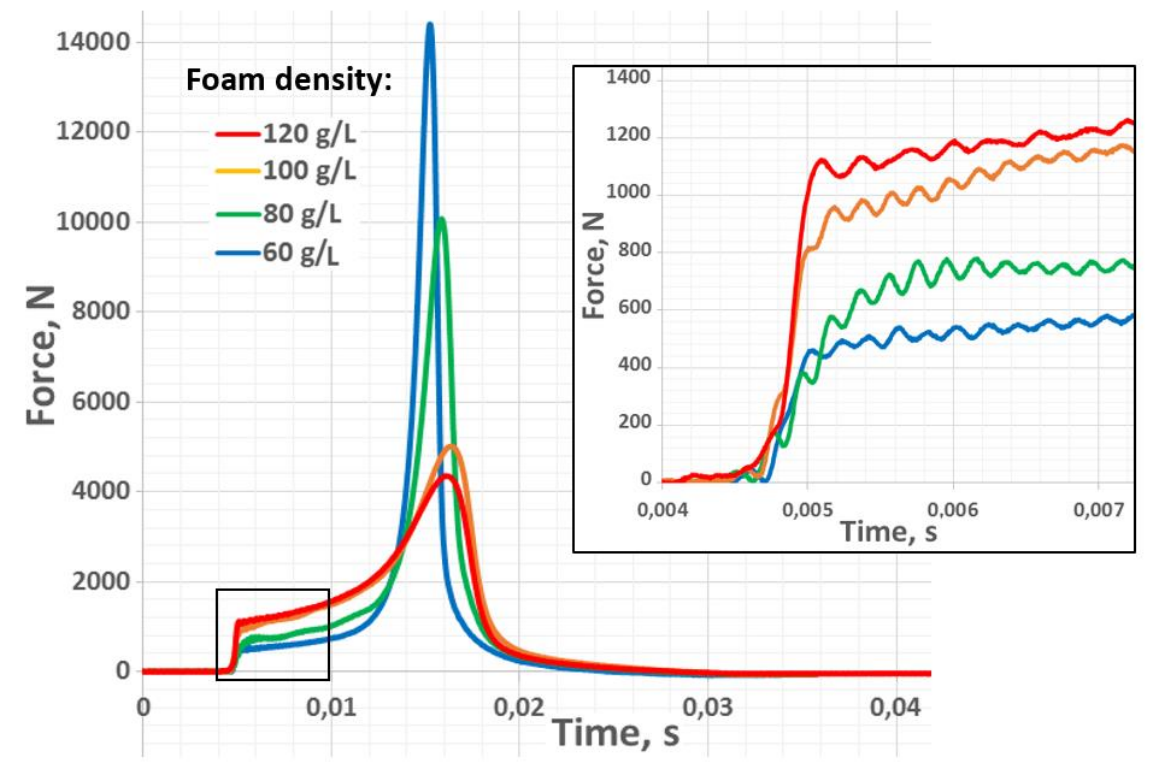

Figure 2. Dynamic compression test results (room temperature $\left(\approx 18^{\circ} \mathrm{C}\right)$ ). 


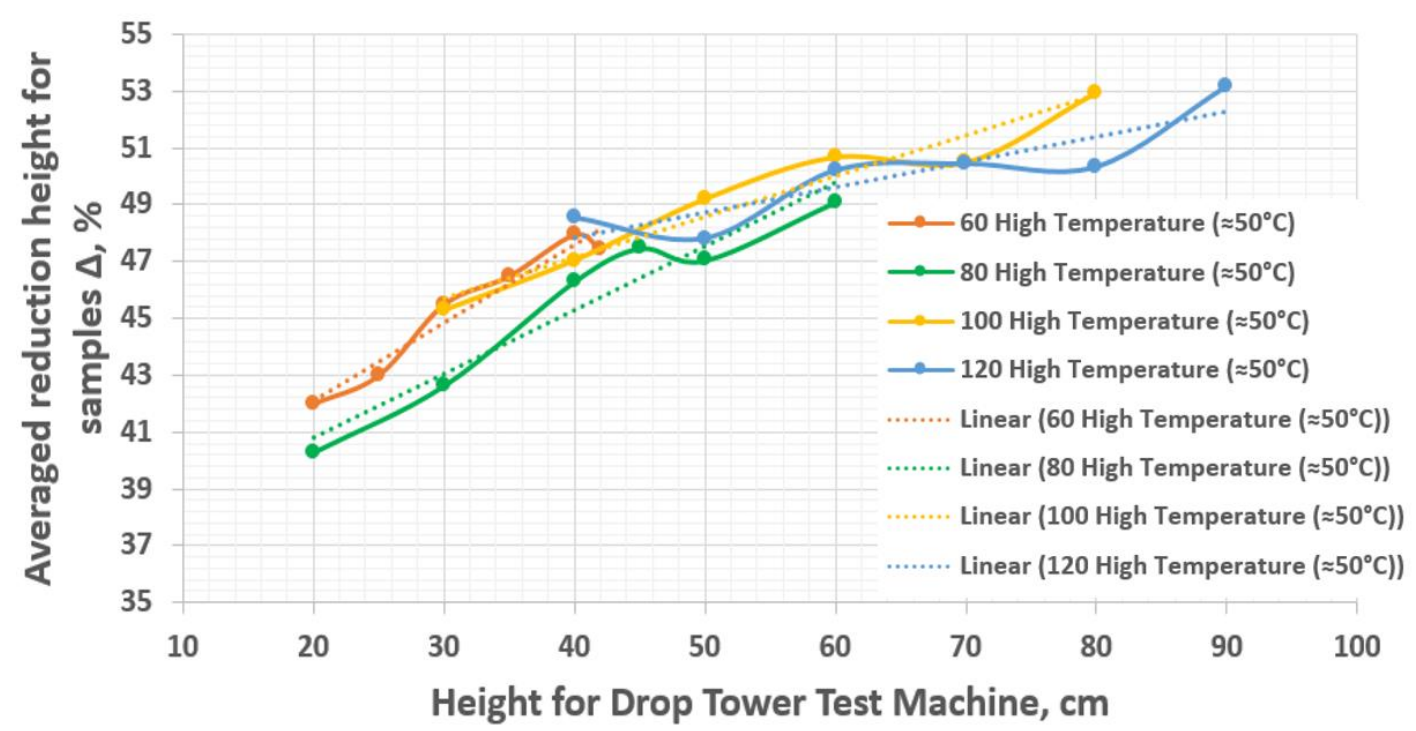

Figure 3. The thickness reduction in the foams for high temperature $\left(\approx 50^{\circ} \mathrm{C}\right)$.

The thickness reduction in foams with low density $(60 \mathrm{~g} / \mathrm{L})$ was observed to be higher. The thickness reduction increased when decreasing the foam density and increasing the drop height of the test machine, as illustrated by the results on Figure 3. The lighter foam (with lower density $60 \mathrm{~g} / \mathrm{L}$ ) is able to absorb the prescribed amount of energy with large deformations because there is a low-value plateau and the foam starts to become more dense. On the contrary, the heavier foam (with higher density $120 \mathrm{~g} / \mathrm{L}$ ) does absorb the same amount of energy with low deformation and high force, which means the density has a major influence in the dynamic compression of cellular materials. The samples with density $100 \mathrm{~g} / \mathrm{L}$ and $120 \mathrm{~g} / \mathrm{L}$ showed a smaller change in the residual thickness for both low temperature $(\approx-$ $20^{\circ} \mathrm{C}$ ) and high temperature $\left(\approx 50^{\circ} \mathrm{C}\right)$, compared to the other densities of $60 \mathrm{~g} / \mathrm{L}$ and $80 \mathrm{~g} / \mathrm{L}$. The ideal foam is that with intermediate density $80 \mathrm{~g} / \mathrm{L}$ and $100 \mathrm{~g} / \mathrm{L}$. By plotting (Figure 2) the maximum force that is reached by the four different foam specimens to absorb the same prescribed amount of energy, it is possible to determine the optimal density for the application.

Also, it was observed that the temperature has an influence on the results. The compression force of the EPS foam $120 \mathrm{~g} / \mathrm{L}$ decreased on $17 \%$ when increasing the temperature from $-20^{\circ} \mathrm{C}$ to $50^{\circ} \mathrm{C}$. The results of the temperature effect during the dynamic compression test, when the drop tower energy was $47.97 \mathrm{~J}$, are plotted in Figure 4 . The same effect was gotten for another type of EPS foam. 


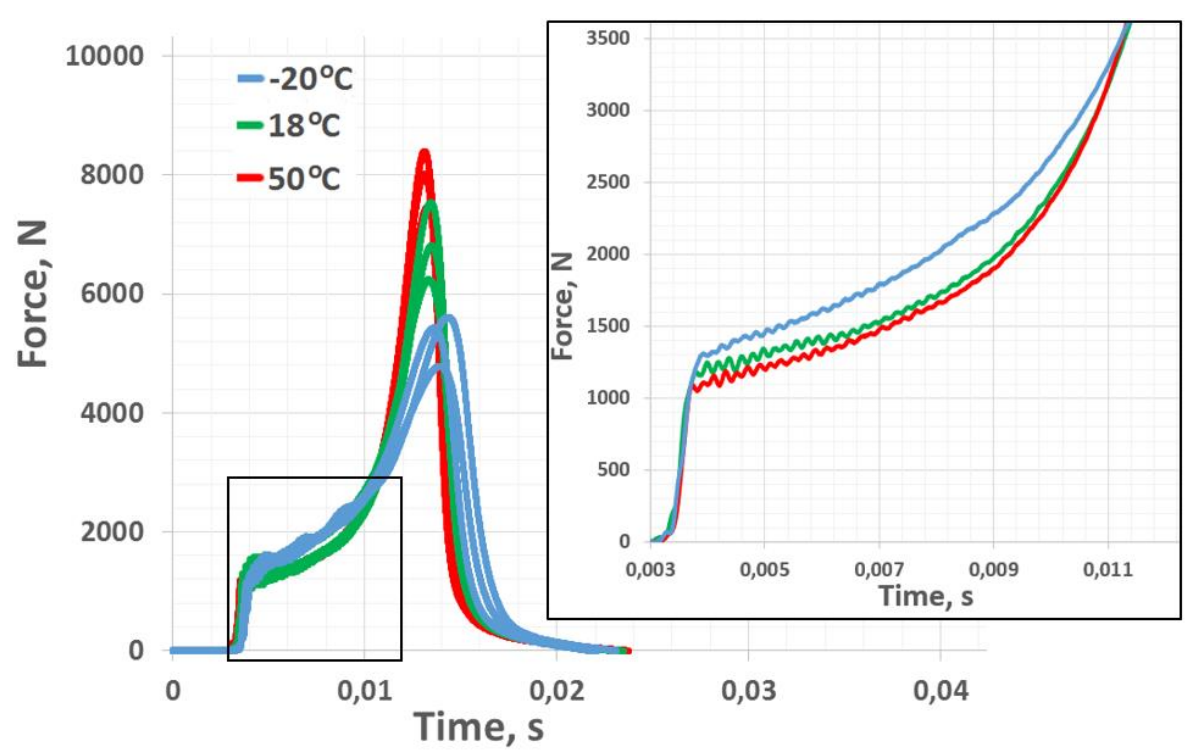

Figure 4. Temperature effect during dynamic compression test (Foam density = $120 \mathrm{~g} / \mathrm{L}$ ).

Polymeric foam exhibits a certain degree of strain rate sensitivity through increased elastic modulus, plateau stress and decreased densification strain $[27,28]$. The results of the measurements are showed in Figure 5. The strain rate is not constant during the compression, although the strain rate has a relatively small influence on the foam properties [29]. Conventional force-displacement data was obtained from the impact tests and converted to stress-strain data using the sample dimensions.

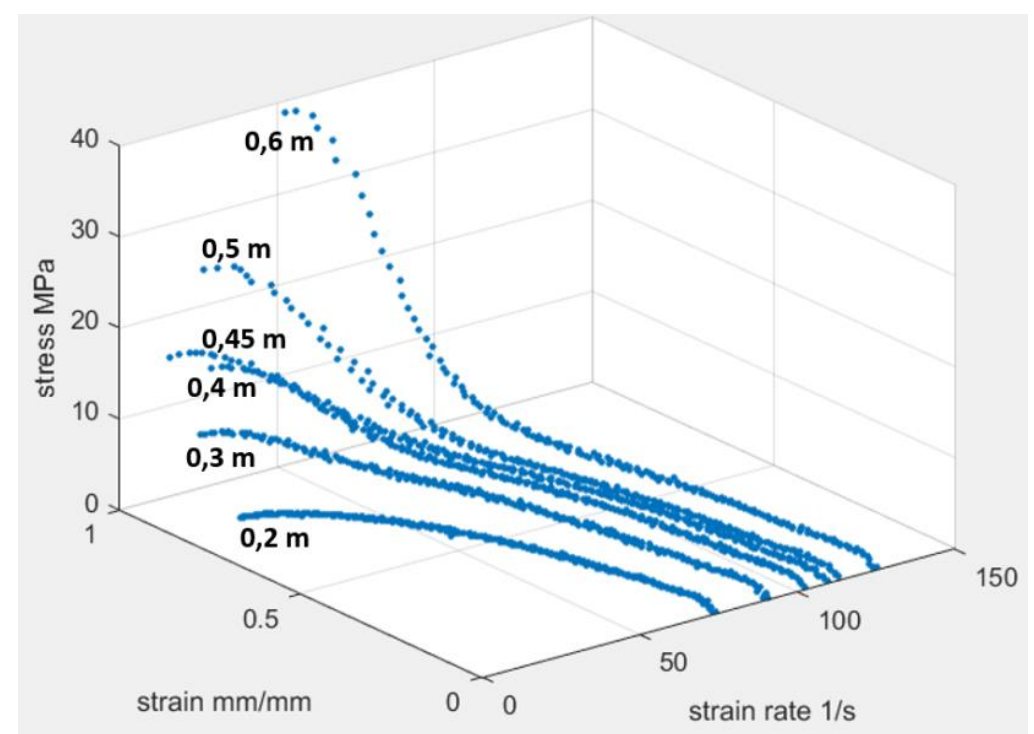

Figure 5. Strain rate, stress and strain history corresponding to different impact heights (Foam density $=80 \mathrm{~g} / \mathrm{l}$, room temperature $\left.\left(\approx 18^{\circ} \mathrm{C}\right)\right)$. 
However, dynamic stress-strain curves need to be defined at a constant strain rate for reliably modelling the EPS performance under dynamic loading and the format must be adapted for use in the finite element program. In this case, interpolation was performed between the true experimental results on the generated $\mathrm{XY}$ grid. Linear interpolation has been used in both $\mathrm{X}$ - and Y-direction. The results of interpolation are listed in Figure 6.

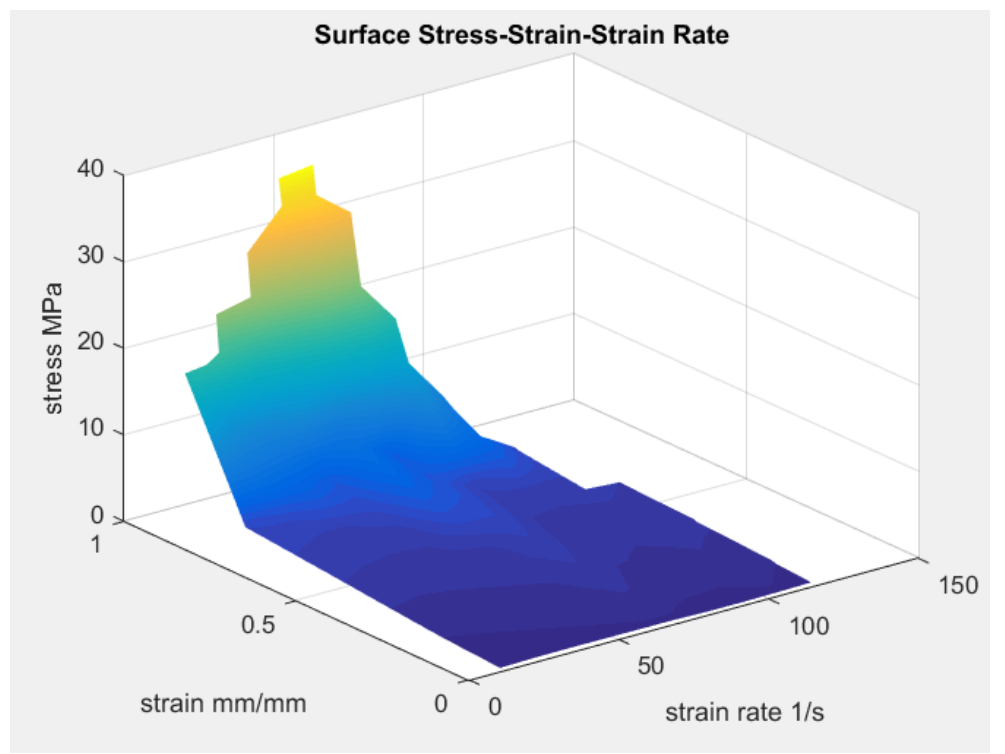

Figure 6. Response surface for Stress-Strain-Strain rate (Foam density $=80 \mathrm{~g} / \mathrm{L}$, room temperature $\left(\approx 18^{\circ} \mathrm{C}\right)$ ).

Then this surface was cut in the strain rate direction and the stress-strain curves at constant strain rate were obtained for the modelling. The stress-strain curves are shown in Figure 7. 


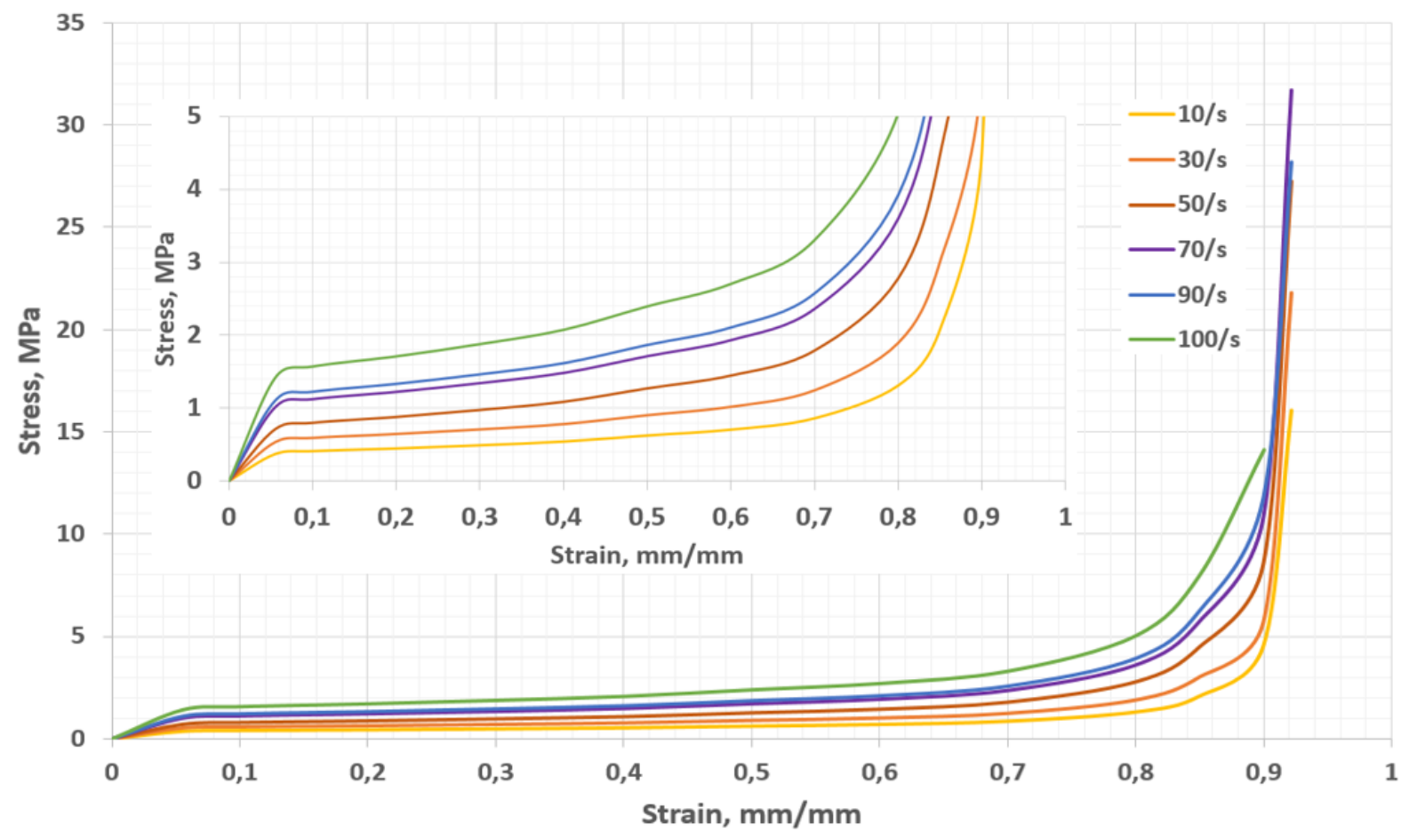

Figure 7. Stress strain curve for different strain rate (Foam density $=80 \mathrm{~g} / \mathrm{L}$, room temperature $\left(\approx 18^{\circ} \mathrm{C}\right)$ ).

\section{Numerical simulation}

\section{Uniform foam model}

There are many studies in literature that present constitutive models and methods for calculating the foam behaviour $[11,12,17]$. EPS foam is a particle foam made by expanding polystyrene beads that contain a blowing agent - usually pentane. Steam heating causes the beads to expand, and the final shape is achieved by moulding the pre-expanded beads with steam and pressure [30]. In this experimental work, CT-scan images of all types of EPS foam were created and analysed before and after dynamic compression. When a foam is compressed, the beads walls start to bend and cause a linear elastic deformation. Beyond a critical strain, the beads collapse by elastic buckling. Whenever the opposing beads walls contact each other, beads collapse. As the beads close up, the structure densifies and its stiffness increases rapidly. The in-plane stiffness and strength are the lowest because the beads walls respond to external loads, by bending, and subsequent buckling, yielding, or fracturing. The out-of-plane stiffness and strength are much larger since they require axial deformation of the beads walls. During this experimental work, no internal damage was observed in the specimens. This result allowed for the creation of a uniform foam model. The 
results of EPS foam $60 \mathrm{~g} / \mathrm{L}$ before and after the dynamic compression test at low temperature $\left(\approx-20^{\circ} \mathrm{C}\right)$, when the drop tower energy was $47.97 \mathrm{~J}$, are plotted in Figure 8.

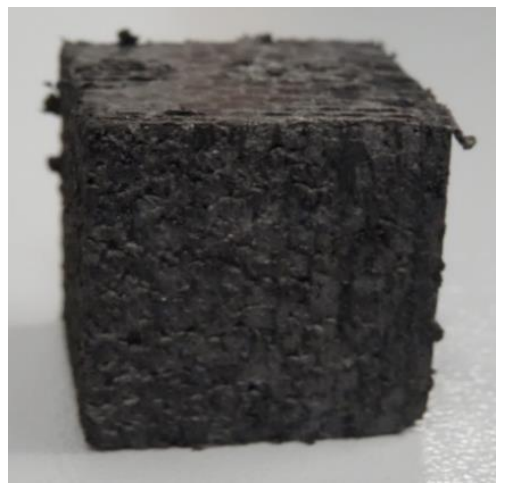

a) Before compression test

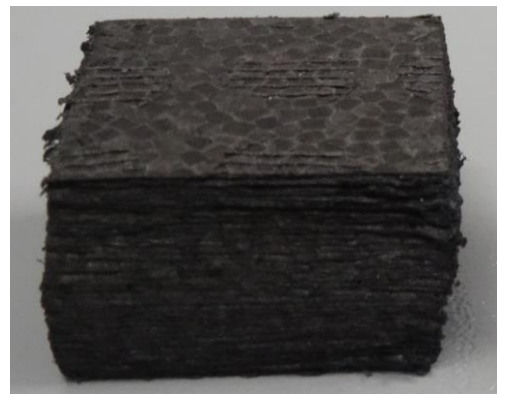

b) After dynamic compression test
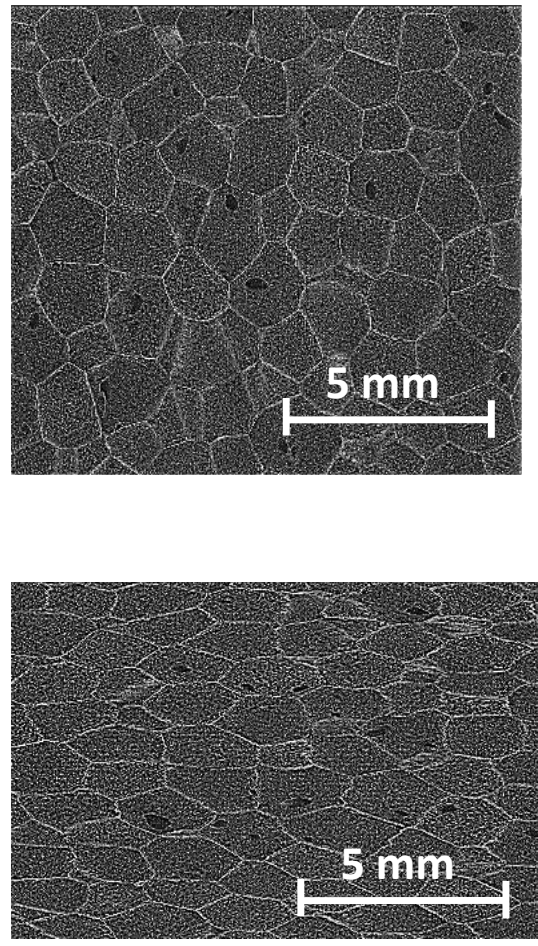

Figure 8. CT-scan images of EPS foam before and after dynamic compression test (Foam density $=60 \mathrm{~g} / \mathrm{L}$, low temperature $\left.\left(\approx-20^{\circ} \mathrm{C}\right)\right)$.

\section{Dynamic compression test simulation}

In this work was used commercial software to predict the experimental result. The simulation of the dynamic compression test was successfully performed using LS-Dyna. LS-Dyna provides many material models for different types of foam [31,32]. However, based on previous work by Shah and Topa [16], the best candidate for modelling EPS foam is MAT_MODIFIED_CRUSHABLE_FOAM. This is a material model which is dedicated to modelling crushable foam with optional damping, tension cut-off, and strain rate effects. Unloading is fully elastic. Tension is treated as elastic-perfectly-plastic at the tension cut-off value. The intent of this type of material model is to simulate crushable foams in side impact and other applications where cyclic behaviour is unimportant. In the implementation we assume that the Young's modulus is constant and update the stress, assuming elastic behaviour: 


$$
\sigma_{i j}^{\text {trial }}=\sigma_{i j}^{n}+E \dot{\varepsilon}_{i j}^{n+\frac{1}{2}} \Delta t^{n+\frac{1}{2}}
$$

The magnitudes of the principal values, $\sigma_{i}^{\text {trial }}, i=1,3$ are then checked to see if the yield stress, $\sigma_{y}$, is exceeded and if so they are scaled back to the yield surface:

$$
\text { If } \sigma_{y}<\left|\sigma_{i}^{\text {trial }}\right| \text { then } \sigma_{i}^{n+1}=\sigma_{y} \frac{\sigma_{i}^{\text {trial }}}{\left|\sigma_{i}^{\text {trial }}\right|} \text {. }
$$

After the principal values are scaled, the stress tensor is transformed back into the global system. As seen in Figure 9, the yield stress is a function of the natural logarithm of the relative volume, $V$, i.e., the volumetric strain. It allows the yield stress to be a function of both volumetric strain rate and volumetric strain. Rate effects are accounted for by defining a table of curves using *DEFINE_TABLE. Each curve defines the yield stress versus volumetric strain for a different strain rate. The yield stress is obtained by interpolating between the two curves that bound the strain rate [31].

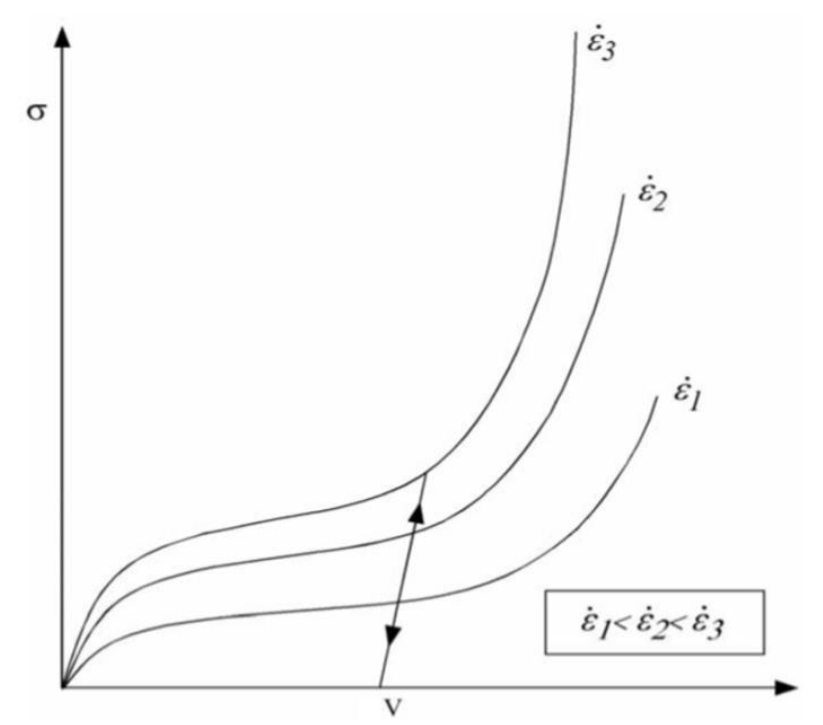

Figure 9. Rate effects are defined by a family of curves giving yield stress versus volumetric strain.

This material model required the input of six parameters: density of material, modulus of elasticity, Poisson's ratio, stress strain curves, tensile stress cut-off and viscous damping coefficient. Most parameters were found experimentally. However, the tensile stress cut-off $\left(\mathrm{TSC}=1 \cdot 10^{-3} \mathrm{GPa}\right)$ and viscous damping coefficient $(\mathrm{DAMP}=0.1$ ) were obtained from the literature [16]. 
A mesh convergence study was done to investigate the effect of using different mesh refinements on the energy absorption and peak load result. From that, the converged mesh values were used in the model analysis with application of various parameters such as hourglass control and element formulation. At the end the model was finely meshed to obtain accurate results. The element side length should be $2.5 \mathrm{~mm}$ to ensure correct mesh deformation prediction during the simulation. A constant stress solid element was chosen with Flanagan-Belytschko stiffness form hourglass control [33].

The lower nodes of the model made contact with the plate while the upper nodes made contact with the impactor. AUTOMATIC_SURFACE_TO_SURFACE contact was used in both contact areas. To avoid mesh collapsing in high compression areas, interior contact was utilized with an activation thickness factor of 0.1 . Contact interior type 2 was activated to control a combined mode of compression and shear in LS-DYNA [34]. The impactor was given an initial velocity and gravity load. The impactor was modelled like a RIGID_BODY. Its mass and dimensions were according to the Drop Tower test machine.

Figure 10 shows the evolution of the compression test. The EPS foam ( $80 \mathrm{~g} / \mathrm{L}$ ) was impacted with a flat anvil at low temperature $\left(\approx-20^{\circ} \mathrm{C}\right)$, when the drop tower energy was $57.6 \mathrm{~J}$.
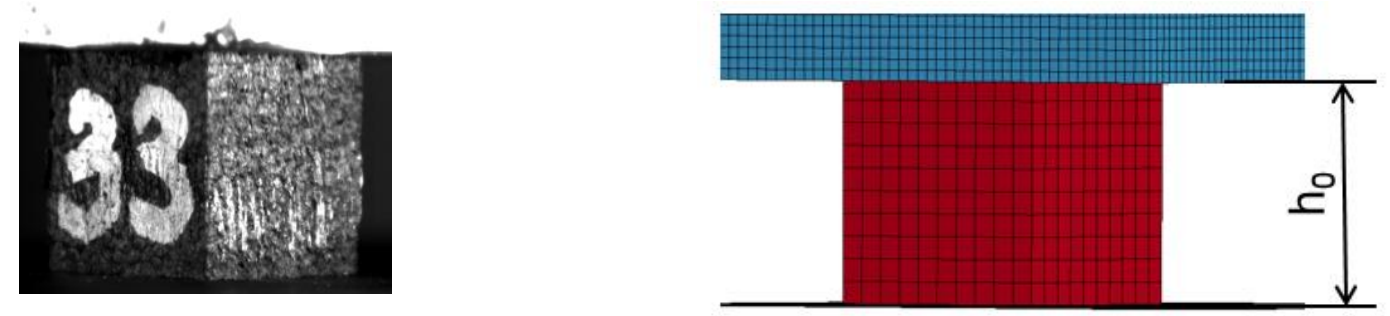

a) First time of contact, $h_{0}=25 \mathrm{~mm}$;
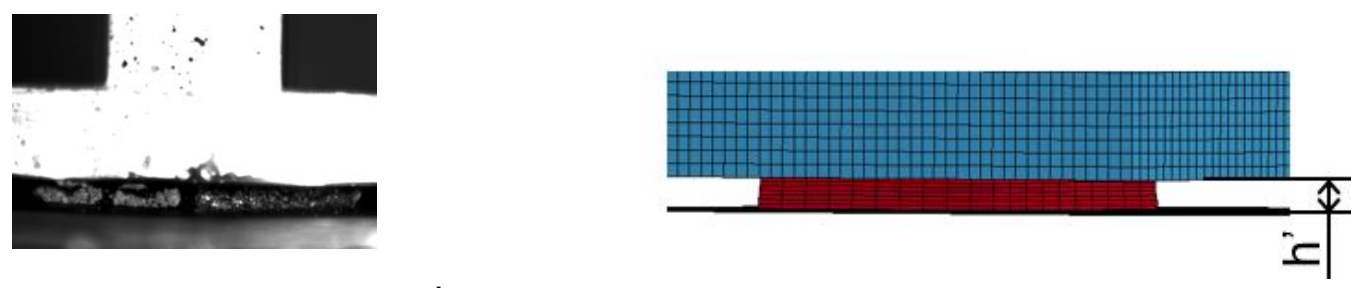

b) Full compression of the EPS foam, $h^{\prime}=2.3 \mathrm{~mm}$;

Figure 10. The deformation of the numerical model of EPS foam and comparison with the experimental result (Foam density $=80 \mathrm{~g} / \mathrm{l}$, low temperature $\left(\approx-20^{\circ} \mathrm{C}\right)$ ). 
Numerical methods in engineering are used to solve coupled partial differential equations, which describe the key physics, using discretization of the time and space variables. One of the popular Grid Convergence Index (GCI) [35] provides a discretization error estimate even when the successive mesh refinements are not integer multiples, i.e. doubling the mesh is not required. The $\mathrm{GCl}$ is stated as an error percentage and provides a confidence bound on the estimated error band within which the numerically converged solution will likely lie. The $\mathrm{GCl}$ was applied to get the correct discretization in this task. The results of the simulation for EPS foam with density $80 \mathrm{~g} / \mathrm{L}$ at low temperature $\left(\approx-20^{\circ} \mathrm{C}\right)$ are listed in Figure 11 . A comparison between the simulation and the experimental results shows very small differences and thus verifies the material model developed for dynamic compression.

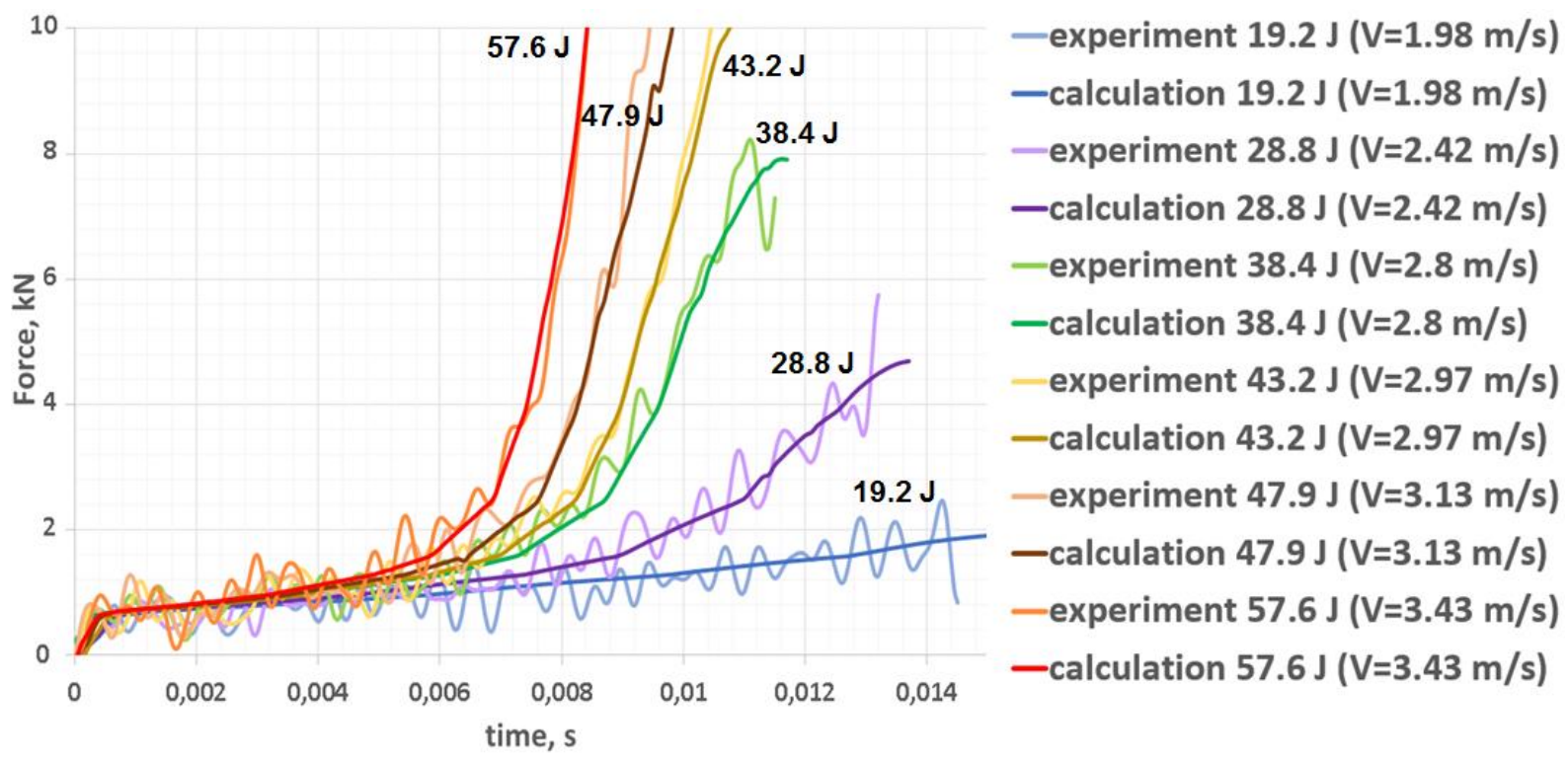

Figure 11. Comparison between the experimental and simulation results of the dynamic compression test (Foam density $=80 \mathrm{~g} / \mathrm{L}$, low temperature $\left(\approx-20^{\circ} \mathrm{C}\right)$ ).

The constructed models can be used for different ranges of material strain rates. Their reliability for predicting the energy absorption was judged by comparing several experimental and numerical results for different impact configurations. The quality of the achieved results was compared with the dynamic compression test results. 


\section{Validation of the model's parameters}

Validation of the model's parameters is possibly the most important step in the model building sequence. Validation was done with tests using the "kerbstone" support (Figure 12), because it can be applied to the foam material to estimate the impact of bicycle helmets.

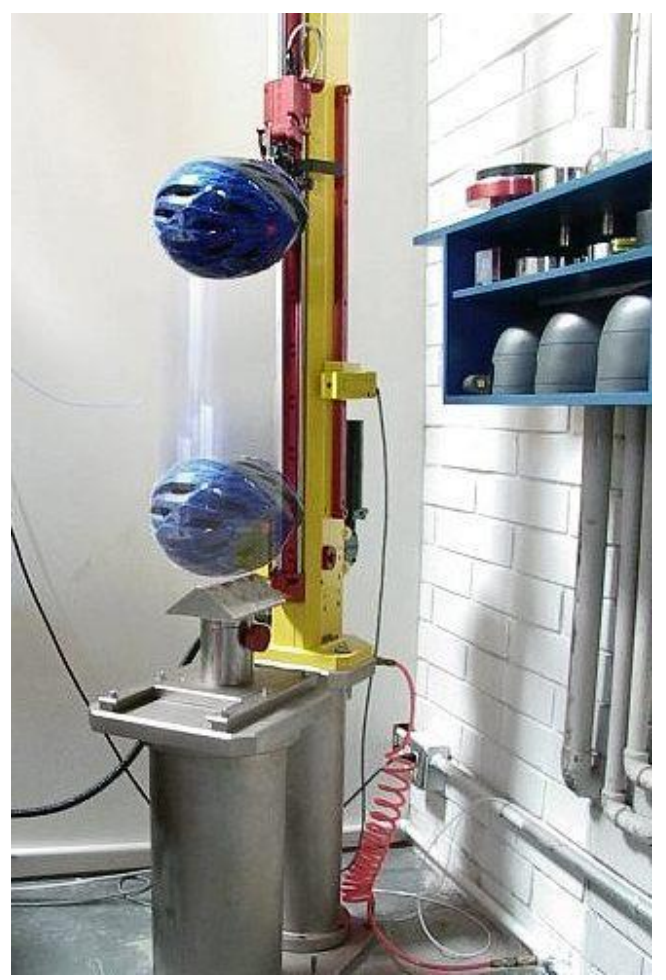

Figure 12. Test with "kerbstone" support.

The drop test of the bicycle helmet on a "kerbstone" is part of the European test standards EN1078 [5]. The deformation of EPS foam at room temperature $\left(\approx 18^{\circ} \mathrm{C}\right)$, when the drop tower energy was $115.1 \mathrm{~J}$, is shown in Figure 13 . The EPS foam density was $80 \mathrm{~g} / \mathrm{L}$.

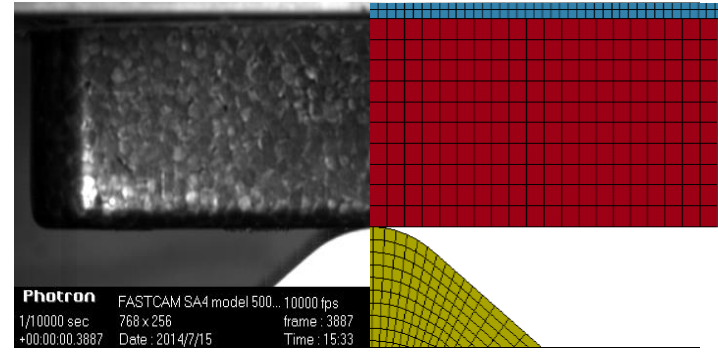

a) First time of contact;

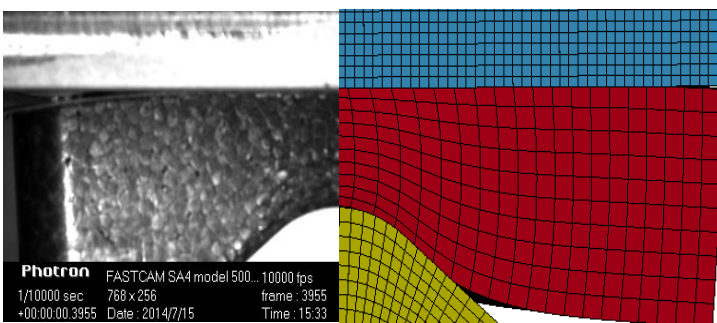

b) Full compression of the foam;

Figure 13. The deformation of the numerical model of EPS foam compared to the experimental result (Foam density $=80 \mathrm{~g} / \mathrm{L}$, room temperature $\left(\approx 18^{\circ} \mathrm{C}\right)$ ). 
In this case the same stress-strain curve for the material model of EPS foam was used as in the previous simulation, without any change to the material model parameters. For modelling shear deformation, a Poisson's ratio of 0.3 was applied [36]. The kerbstone was modelled as a rigid body. The results of the validation are plotted in Figure 14 and 15. The simulations show good correlation with the experimental data. The results were computed by using the same material model for different experimental drop heights, foam densities and temperatures for the kerbstone experiments.

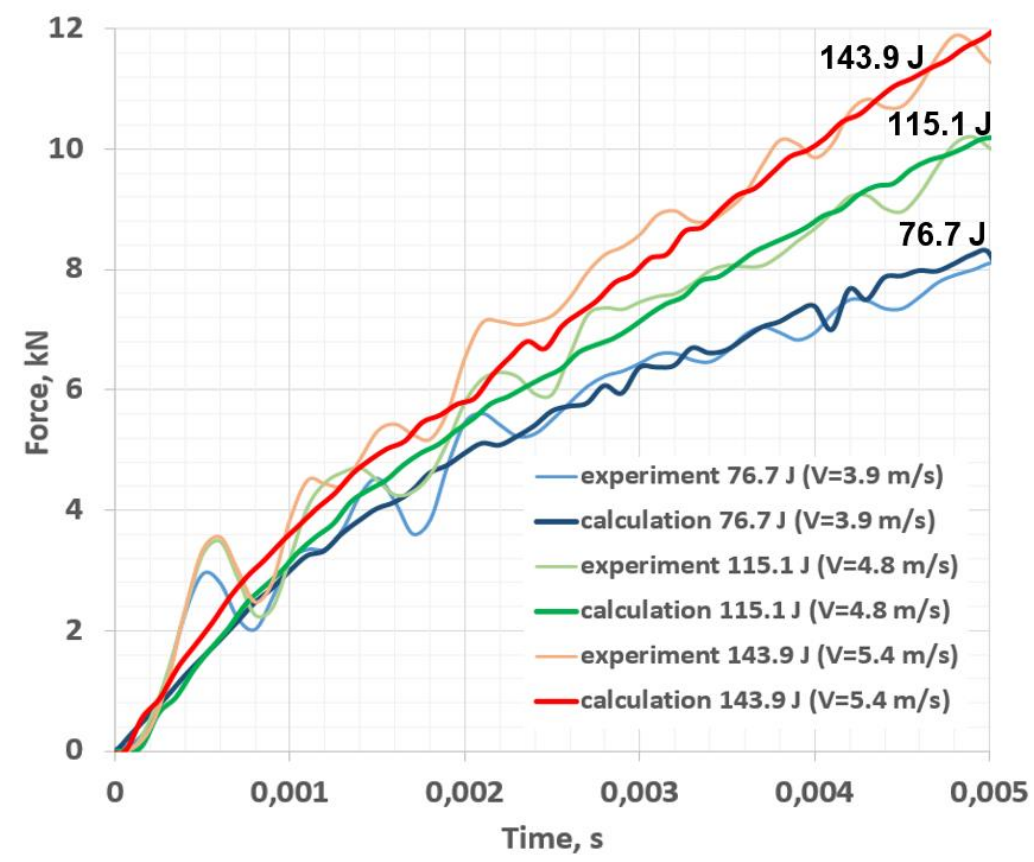

Figure 14. Validation result with kerbstone (Foam density $=80 \mathrm{~g} / \mathrm{L}$, room temperature $\left(\approx 18^{\circ} \mathrm{C}\right)$ ).

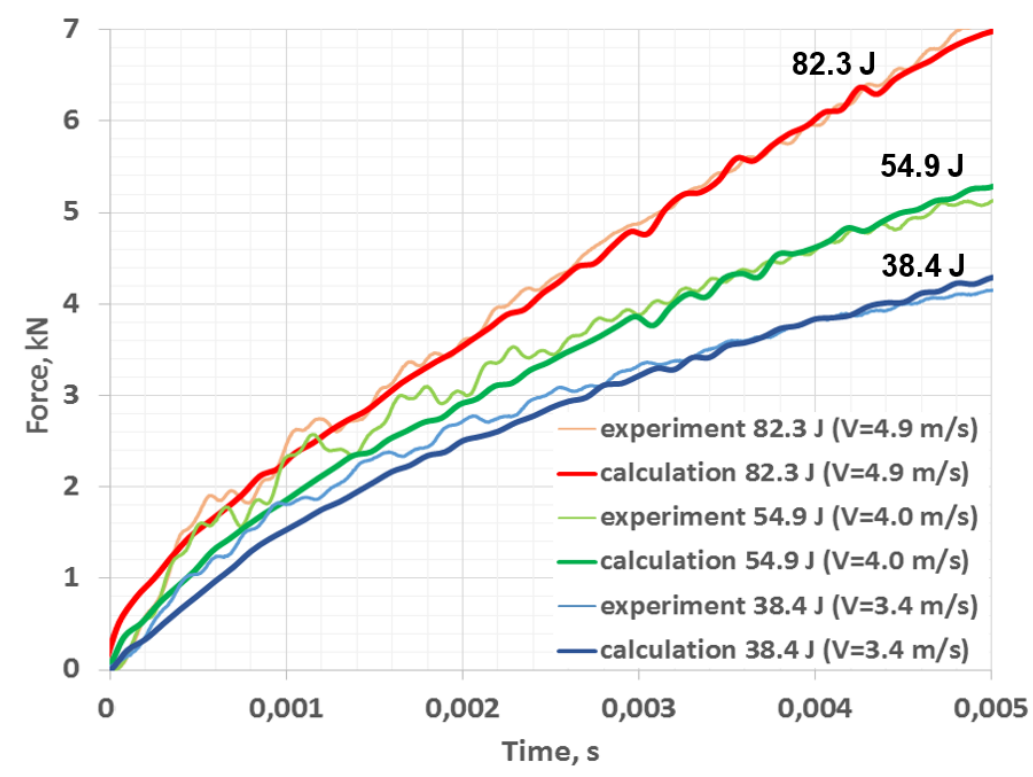

Figure 15. Validation result with kerbstone (Foam density $=60 \mathrm{~g} / \mathrm{L}$, high temperature $\left(\approx 50^{\circ} \mathrm{C}\right)$ ). 


\section{Conclusions}

In this research, the dynamic compression and crushing characteristics of the EPS foam were quantified at different strain rates (10/s, 30/s, 50/s, 70/s, 90/s, 100/s), four densities $(60 \mathrm{~g} / \mathrm{L}, 80 \mathrm{~g} / \mathrm{L}, 100 \mathrm{~g} / \mathrm{L}$ and $120 \mathrm{~g} / \mathrm{L})$ and three temperatures $\left(\approx-20^{\circ} \mathrm{C}, \approx 18^{\circ} \mathrm{C}, \approx 50^{\circ} \mathrm{C}\right)$. The results show a relatively small effect of the strain rate on the material properties of EPS. Density was found to be the most significant parameter affecting the mechanical properties of EPS foam during dynamic compression. The strength in foams with low density $(60 \mathrm{~g} / \mathrm{L})$ is $50 \%$ less than in foams with high density $(120 \mathrm{~g} / \mathrm{L})$. Temperature has an influence on the foam properties too. The strength of the EPS foam is decreased by $13 \%$ when the temperature increases to $50^{\circ} \mathrm{C}$. And opposite, the strength of the EPS foam is increased by $8 \%$ upon the temperature decrease to $-20^{\circ} \mathrm{C}$.

Compression tests were conducted for obtaining the material properties of EPS foam as well as to fill a material model in LS-Dyna. The most important properties to include in the material model are the density and stress strain curve. These properties were quantified experimentally. The stress-strain curve was found to be dependent on the strain rate. As the strain rate increases, the stress-strain curve becomes stiffer.

Dynamic compression tests were also simulated in a commercial software to predict the experimental result. Results were validated with experimental data and show that the material parameters was capable to reproduce the stress-strain curve with very precise accuracy. Therefore, the material parameters are capable of accurately predicting the load and deformation of EPS foams. The results obtained from the validation of the model's parameters are in good agreement with the experimental ones.

The authors gratefully acknowledge SIM (Strategic Initiative Materials in Flanders) and VLAIO (Flanders Innovation \& Entrepreneurship agency) for their support of the IBO project M3Strength, which is part of the research program MacroModelMat (M3).

\section{References}

1. Avalle M, Belingardi G, Montanini R. Characterization of polymeric structural foams under compressive impact loading by means of energy-absorption diagram. International Journal of Impact Engineering, 25, pp. 455-472, 2001.

2. Di Landro L, Sala G, Olivieri D. Deformation mechanisms and energy absorption of polystyrene foams for protective helmets. Polymer Testing 21 (2002) 217-228. 
3. Horvath J. Expanded polystyrene (EPS) geofoam: an introduction to material behaviour. Geotext Geomembr 1994;13(4):263-80.

4. Viot P, Plougonven E, Bernard D. Microtomography on polypropylene foam under dynamic loading: 3D analysis of bead morphology evolution. Composites: Part A 39 (2008) 1266-1281.

5. BSEN 1078. Helmets for pedal cyclists and for users of skateboards and roller skates. British Standards Institution, London, October 2012.

6. Saint-Michel F, Chazeau L, Cavaille J, Chabert E. Mechanical properties of high density polyurethane foams: I. Effect of the density. Composites Science and Technology 66 (2006) 2700-2708.

7. Chen W, Lu F, Winfree N. High-strain-rate Compressive Behavior of a Rigid Polyurethane Foam with Various Densities. Experimental Mechanics, Vol. 42, No. 1, 65-73, March 2002.

8. Bouix R, Viot P, Lataillade J. Polypropylene foam behaviour under dynamic loadings: Strain rate, density and microstructure effects. International Journal of Impact Engineering 36 (2009) 329-342.

9. Avalle M, Belingardi G, Montanini R. Characterization of polymeric structural foams under compressive impact loading by means of energy-absorption diagram. International Journal of Impact Engineering 25 (2001) 455-472.

10. Saint-Michel F, Chazeau L, Cavaille J. Mechanical properties of high density polyurethane foams: II Effect of the filler size, Composites Science and Technology 66 (2006) 2709-2718.

11. Mills NJ, Stämpfli R, Marone F, Brühwiler PA Finite element micromechanics model of impact compression of closed-cell polymer foams. International Journal of Solids and Structures, 46 (2009) 677-697.

12. Ajdari A. Mechanical behavior of cellular structures: a finite element study. Northeastern University, Boston, 2008.

13. Chen W, Hao H, Hughes D, Shi Ya, Cui Jia, Li ZX. Static and dynamic mechanical properties of expanded polystyrene. Materials and Design 69 (2015) 170-180.

14. Ouellet $S$, Cronin D, Worswick M. Compressive response of polymeric foams under quasi-static, medium and high strain rate conditions. Polym Test 2006;25(6):731-43.

15. Duškov M. Materials research on EPS20 and EPS15 under representative conditions in pavement structures. Geotext Geomembr 1997;15(1):147-81.

16. Shah QH, Topa A. Modeling Large Deformation and Failure of Expanded Polystyrene Crushable Foam Using LS-DYNA. Hindawi Publishing Corporation Modelling and Simulation in Engineering Volume 2014, Article ID 292647, 7 pages.

17. Ozturk UE, Anlas G. Finite element analysis of expanded polystyrene foam under multiple compressive loading and unloading. Materials and Design 32 (2011) 773-780.

18. Masso-Moreu Y, Mills NJ., Impact compression of polystyrene foam pyramids. Int J Impact Eng 2003;28(6):653-76.

19. Slik G, Vogen G, Chawda V. Material model validation of a high efficient energy absorbing foam. $5^{\text {th }}$ LS-DYNA Forum, Material III - Foam / Composites, 2006. 
20. Ashby M.F. The properties of foams and lattices. Philosophical transactions A: physical, mathematical and engineering sciences. Published 15 January 2006.DOI: 10.1098/rsta.2005.1678.

21. Degrieck J, Accurately measuring position and average strain using a "2D pyjama pattern". UGent EA10-MMS, Internal report, 2015 February 25th , Gent, Belgium.

22. Lu G, Yu T. Energy absorption of structures and materials. Woodhead Publishing; 2003.

23. Gibson L, Ashby M. Cellular solids: structure and properties. Cambridge: Cambridge University Press; 1997.

24. Dou W, Winfree S, Song NA, Chen B, Kang J H. Strain-rate effects on elastic and early cell-collapse responses of a polystyrene foam. International Journal of Impact Engineering 2005;31:509-21.

25. Mills NJ, Lyn G. Modelling of air flow in impacted polyurethane foam. Cellular Polymers 2002;21(5):343-67.

26. Mills NJ, Gilchrist A. Shear and compressive impact of polypropylene bead foam. Cellular Polymers 1999;18(3):157-74.

27. Di Landro L, Sala G, Olivieri D. Deformation mechanisms and energy absorption of polystyrene foams for protective helmets. Polym Test 2002;21(2):217-28.

28. Ouellet $S$, Cronin D, Worswick M. Compressive response of polymeric foams under quasi-static, medium and high strain rate conditions. Polym Test 2006;25(6):731-43.

29. Bouix R, Viot P, Lataillade JL. Polypropylene foam behaviour under dynamic loadings: Strain rate, density and microstructure effects. International Journal of Impact Engineering 36 (2009) 329-342.

30. Nising P. Flexible foam production. Sulzer Technical Review 2/2012.

31. LS-DYNA TheoryManual Version. Vol. R7.1, Livermore Software Technology.

32. Croop B, Lobo H. Selecting material models for the simulation of foams in LS-DYNA. $7^{\text {th }}$ European LS-DYNA Conference, 2009.

33. Weimar K, Day J. Negative volumes in brick elements. http://www.dynasupport.com/howtos/element/negativvolumes-in-brick-elements.

34. Matthew Barsotti MS. Comparison of FEM and SPH for modeling a crushable foam aircraft arrestor bed. 11th International LS-DYNA Users Conference, vol. 16, pp. 37-54, 2010.

35. Roache PJ. Verification and Validation in Computational Science and Engineering, Hermosa Publishers, Albuquerque (1998).

36. Mills NJ, Gilchrist A. Shear and Compressive impact of Polypropylene bead foam. Cellular Polymers, 18(3):157-174, 1999. 